Original Research Paper

\title{
Thermogravimetric Analysis (TGA) Profile at Different Calcination Conditions for Synthesis of PTES-SBA-15
}

\author{
Norhasyimi Rahmat, Nurjihan Sadon and Muhammad Abeed Yusof \\ Faculty of Chemical Engineering, Universiti Teknologi MARA, 40450 Shah Alam, Selangor, Malaysia
}

\author{
Article history \\ Received: 11-10-2015 \\ Revised: $30-10-2016$ \\ Accepted: 29-03-2017 \\ Corresponding Author: \\ Norhasyimi Rahmat \\ Faculty of Chemical \\ Engineering, Universiti \\ Teknologi MARA, 40450 Shah \\ Alam, Selangor, Malaysia \\ Email: norhasyimi@salam.uitm.edu.my
}

\begin{abstract}
The aim of this work is to study the effects of calcination condition on the properties of mesoporous silica, SBA-15 modified with phenyl group of organosilane. Functional group SBA-15 were synthesized and hydrothermally aged. The surfactant template was conventionally removed by calcination at varied temperature and duration. Thermogravimetric Analysis (TGA) was employed to characterize the pure and modified SBA-15. The TGA profile presented here would include modified SBA-15 functionalized using two different methods, directsynthesis and post-grafting. The characterization profile from TGA showed that the temperature of calcination has large influence in determining the effectiveness of surfactant removal and incorporation of alkoxysilane into pure silica whether by post-grafting or direct synthesis method. However, the duration of calcination does not significantly affect these characteristics. Besides, mesoporous structure of SBA-15 by post-grafting method shows higher degree of functionalization than that of direct-synthesis.
\end{abstract}

Keywords: Calcination, Direct-Synthesis, Post-Grafting, Phenyltriethoxysilane, SBA-15, Thermogravimetric Analysis

\section{Introduction}

Porous solid is extensively used as catalyst and adsorbent due to their high surface area. Typical porous material, zeolite has been widely used because of their uniform pore size distribution and good stability (Rowsell and Yaghi, 2004). However, zeolite has small pores size and this limits their application involving large reactant molecule. A new material with larger pore called Santa Barbara Amorphous-15 (SBA-15) has been of recent interest. This type of mesoporous silica with amorphous, hexagonal shape and two-dimension has characteristics of narrow pore size distribution, thermally stable, inert, harmless and cheap (Wua et al., 2006). Their thick wall leads to high thermal and mechanical stability. This make them desirable for catalytic application since catalyst are always exposed to high temperature and steam (Filiz and Ayşen, 2012). However, the disadvantage of SBA-15 that restricts them from behaves effectively as catalyst is their low acidity strength (Norhasyimi et al., 2010). To overcome this problem, SBA-15 is modified by incorporating functional group consists of organosilane such as Vinyltriethoxysilane (VTES), phenyltriethoxysilane (PTES) and Methyltriethoxysilane (MTES) to the structure of SBA-15.
Direct-synthesis is one of the methods to functionalize SBA-15. It involves co-condensation of silica source such as Tetramethylorthosilicate (TMOS) and Tetraethylorthosilicate (TEOS) together with functional group organotrialkoxysilane. This method can be done under neutral, acidic and or alkaline condition. It is an expensive method since it involves large volume of organosilanes. For post-grafting method, the silica is synthesized using same procedure as direct-synthesis and then the free silanol will react with organosilane. Compared to direct synthesis, grafting of pores only take place on outer surface. Grafting of pores in direct synthesis occur both in inner and outer place of pores. Use of postgrafting compared to direct-synthesis resulting in ordered structure and higher hydrothermal stability (García et al., 2007). Although the uses of post-grafting to synthesis mesoporous 3D-hexagonal organosilicate films produce more well-ordered structure, the porosity of silica is reduced (Matheron et al., 2006). Besides that, direct-synthesis results in homogenous distribution of organic group over the surface while post-grafting presents better defined pore sizes (Calvoa et al., 2009).

Modifed SBA-15 using PTES produces particle with more uniform size and shape (Wua et al., 2006). One of 
significant characteristics of PTES is its hydrophobic nature of phenyl group. This hydrophobic nature can be improved by adjusting ratio of phenyl loading and grafting phenyl loaded sample with trimethylchlorosilane (Gokulakrishnana et al., 2013). Due to its hydrophobic characteristics, PTES particle shows low water vapour adsorption (Wua et al., 2006) and small weight loss during TGA analysis (Gokulakrishnana et al., 2013). Because of incorporation of hydrophobic molecule, the hydrothermal stability of membrane can be improved ( $\mathrm{Li}$ et al., 2011). PTES modified silica also results in large pore size but low hydrogen permeances (Li et al., 2011).

Properties of SBA-15 can be amended by factors like hydrothermal treatment, reaction temperatures, surfactants removal and stirring time. They play important roles in determining the wall thickness, pore size and morphology characteristics of mesoporous material. This property affects the hydothermal and mechanical stability which are imperative for their application in catalysis. A work by Benamor et al. (2012) concluded that the factors that strongly affect the structure of SBA-15 are silica condensation rate and surfactant behaviour which are dependent on temperature and duration at ripening and aging step (Benamor et al., 2012). Another research found that the mesoporous diameter and volume of SBA-15 is increased by treatment of heat in aging steps (Klimovaa et al., 2006). Synthesis by using two thermal treatment steps especially the second step are proved to increase the pore size, wall thickness and decrease in microporosity (Brodie-Lindera et al., 2008; Ko and Ryong, 2000).

Surfactants are amphiphilic molecule that is used as structure directing agents. It determines the pore structure and morphological characteristics of SBA-15. These surfactants must be removed to obtain pure solid. It is an essential aspect in deciding the final properties of product. Although there are other alternatives such as chemical removal, washing with ethanol and reflux extraction, the conventional method of surfactant removal is used in this study. The duration and temperature of calcination play important roles in template removal in which carrying out calcination at high temperature may waste large amount of used organic template, produce smell and toxic gases (Huang et al., 2005). Therefore, TGA profile in this study is important to understand the calcination parameter towards incorporation of phenyl group into SBA-15 mesostructure as well as the effectiveness of surfactant removal at different synthesis methods to achieve economical procedure of obtaining better properties of modified SBA-15 in catalysis application.

\section{Methodology}

\section{Materials}

Pluronic 123 triblock copolymer [poly(ethylene oxide)20-poly(propyleneoxide)70-poly(ethylene oxide)20] (P123), tetraorthosilicate (TEOS), 2M hydrochloric acid $(\mathrm{HCl})$, phenyltriethoxysilane (PTES), toluene, $p$-toluenesulfonic acid (PTSA).

\section{Synthesis of Pure SBA-15}

About $4 \mathrm{~g}$ of P123 was dissolved in $125 \mathrm{~mL}$ of $2 \mathrm{M}$ $\mathrm{HCl}$ at room temperature. After complete dissolution, the mixture was heated to $40^{\circ} \mathrm{C}$ on hotplate and $8.6 \mathrm{~g}$ of TEOS was added. The solution was stirred for $20 \mathrm{~h}$ and the temperature was maintained at $40^{\circ} \mathrm{C}$. Then, the white precipitate was hydrothermally aged in oven at $100^{\circ} \mathrm{C}$ for $24 \mathrm{~h}$. The product was recovered and dried. The surfactant was removed by calcination in static air at $550^{\circ} \mathrm{C}$ for $5 \mathrm{~h}$ using furnace.

\section{Synthesis of PTES-SBA-15 by Direct-Synthesis}

About $4 \mathrm{~g}$ of $\mathrm{P} 123$ was dissolved in $125 \mathrm{~mL}$ of $2 \mathrm{M}$ $\mathrm{HCl}$ at room temperature. After complete dissolution, the mixture was heated to $40^{\circ} \mathrm{C}$ on hotplate and $8.6 \mathrm{~g}$ of TEOS was added. PTES was added in TEOS:PTES molar ratio of $15: 1$. The solution was stirred for $20 \mathrm{~h}$ and the temperature was maintained at $40^{\circ} \mathrm{C}$. Then, the white precipitate was hydrothermally aged at $100^{\circ} \mathrm{C}$ for $24 \mathrm{~h}$ in oven. The product was recovered and dried. The surfactantwas removed by calcination in static air using furnace. During calcination, the temperature was varied for 350 and $550^{\circ} \mathrm{C}$ and the duration was varied for $3 \mathrm{~h}$ and $5 \mathrm{~h}$.

\section{Synthesis of PTES-SBA-15 by Post-Grafting}

About $1 \mathrm{~g}$ of SBA-15 and $150 \mathrm{~mL}$ toluene were dissolved in 3 flask equipped with mechanical agitator. The dissolved mixture was stirred for $30 \mathrm{~min}$. at $50^{\circ} \mathrm{C}$. $0.007 \mathrm{~g}$ of PTSA and PTES were added in TEOS:PTES molar ratio of 15:1. After stirring for $2 \mathrm{~h}$, the sample was filtered and hydrothermally aged at $100^{\circ} \mathrm{C}$ for $24 \mathrm{~h}$ in oven. Calcination was carried out in static air using furnace. The calcination temperature was varied for 450 and $750^{\circ} \mathrm{C}$.

\section{Characterization}

TGA was conducted in presence of nitrogen as inert purge with flow of $100 \mathrm{~mL} \mathrm{~min}^{-1}$ and heating rate of $10^{\circ} \mathrm{C} / \mathrm{min}$, heating from 20 to $900^{\circ} \mathrm{C}$.

\section{Results and Discussion}

TGA is used to measure the weight loss during heating of sample. It can determine the presence of material containing carbon, hydrogen, oxygen on the surface of silica such as surfactants (Giaquinto, 2012). 
TGA also can detect the amount of alkoxysilane group incorporated to pure SBA-15 sample. The alkoxysilane in this case is PTES.

Pure SBA-15 in Fig. 1 shows an initial weight loss from 30 to $100^{\circ} \mathrm{C}$. Above $100^{\circ} \mathrm{C}$, very small weight loss was identified. This shows that SBA-15 has good thermal stability within the temperature range.

Figure 2 shows the functionalization of SBA-15 using direct synthesis at different temperature and calcination duration time while Fig. 3 shows the TG curve of fucntionalization of SBA-15 using post-grafting method. Both samples of functionalized SBA-15 in Fig. 2 and 3 show good thermal stability, good term with thermal properties of pure SBA-15. All samples showed weight loss at temperature $30-100^{\circ} \mathrm{C}$ due to loss of moisture. Samples also shows weight loss at temperature above $100^{\circ} \mathrm{C}$ for different method of synthesis and different calcination temperature as well as calcination duration time. These differences are further elaborated at Fig. 4 until Fig. 7, in which the amount of loss are clearly depicted by weight loss percentage.

TGA Profile of PTES-SBA-15 at Different Calcination Temperature using Direct-Synthesis

Figure $4 \mathrm{a}$ and $\mathrm{b}$ display the TG curve of pure SBA-15, PTES-SBA- 15 calcined at $550^{\circ} \mathrm{C}$ and $350^{\circ} \mathrm{C}$. Samples were labeled as PTES-SBA-15(550) and PTES-SBA-15(350) respectively. All samples were calcined for $3 \mathrm{~h}$.

For temperature range of 25 to $150^{\circ} \mathrm{C}$, all three samples show a significant weight loss which was due to loss of adsorbed water. According to Wua et al. (2006) the weight loss below $150^{\circ} \mathrm{C}$ was due to water evaporation. The weight loss for PTES-SBA-15 sample during first region does not differ much with pure SBA15. This proved the hydrophobicity of phenyl group present in PTES functionalized silica. Small weight loss indicates that the water adsorbed in the material is less due to hydrophobic characteristic of PTES. However, when comparing the functionalized sample with pure sample, both functionalized sample exhibit higher weight loss than the pure SBA-15. This could be due to the removal of unreacted phenyl group of PTES present in functionalized sample (Li et al., 2011).

Most of surfactants (P123) decompose between 150 to $250^{\circ} \mathrm{C}$ (Johansson, 2010). This is also in accordance with the result analyzed by (Kruk and Jaroniec, 2001). It is stated that, under nitrogen atmosphere, ionic surfactant template in pure silica usually decompose completely at much lower temperature, below $300^{\circ} \mathrm{C}$ (Ko and Ryong, 2000). Hence, the weight loss for temperature range of 150 to $300^{\circ} \mathrm{C}$ as shown in $\mathrm{TG}$ curve from Fig. 4 is due to the decomposition of surfactants.
From Fig. 4. a and b, it is shown that PTES-SBA15(350) exhibit higher weight loss than PTES-SBA15(550) due to decomposition of surfactants. This indicates that the remaining surfactants are not being removed efficiently at calcination temperature of $350^{\circ} \mathrm{C}$. The surfactants are still remain in sample PTES-SBA15(350). Therefore, it can be concluded that, calcination at $550^{\circ} \mathrm{C}$ are more efficient in removing surfactant compare to at $350^{\circ} \mathrm{C}$.

For temperature range of 300 to $800^{\circ} \mathrm{C}$, the weight loss is due to decomposition of organic group (Wua et al., 2006). Both SBA-15 and PTES-SBA-15(550) do not show significant weight loss while the PTES-SBA15(350) shows a significant weight loss. This significant weight loss is contributed to the decomposition of phenyl group PTES anchored onto the silica surface. It can be hypothesized that functionalization of phenyl group into SBA-15 is more effective at temperature $350^{\circ} \mathrm{C}$ compare to that of $550^{\circ} \mathrm{C}$.

\section{TGA Profile of PTES-SBA-15 at Different Duration Time of Calcination by Direct-Synthesis Method}

Figure $5 \mathrm{a}$ and $\mathrm{b}$ show the TGA profile of PTESSBA-15 of different duration calcination time by direct-synthesis method. Functionalized sample calcined for $5 \mathrm{~h}$ is indicated by PTES-SBA-15(5) while functionalized sample calcined for $3 \mathrm{~h}$ is indicated by PTES-SBA-15(3). The first region of mass loss was due to evaporation of water occurred within temperature range of 25 to $150^{\circ} \mathrm{C}$. The weight loss of PTES-SBA-15(3) is higher than PTES-SBA-15(5) in these range. This is due to the decomposition of remaining PTES that are unreacted during synthesis.

For $\mathrm{TG}$ curve region between 150 to $300^{\circ} \mathrm{C}$, the weight loss of PTES-SBA-15(5) is slightly higher than PTES-SBA-15(3). This could be due to the amount of surfactant of PTES-SBA-15(5) decomposed at calcination duration is higher than PTES-SBA-15(3).

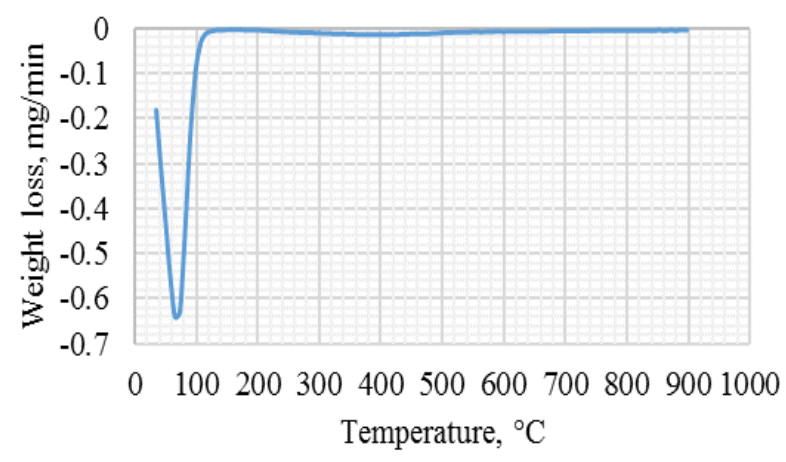

Fig. 1. TG curve for pure SBA-15 


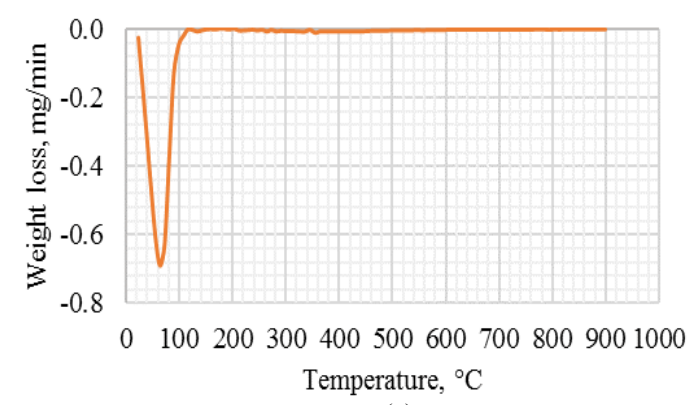

(a)

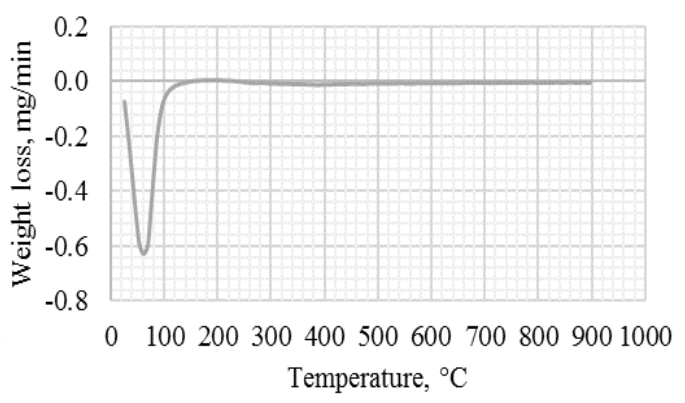

(b)

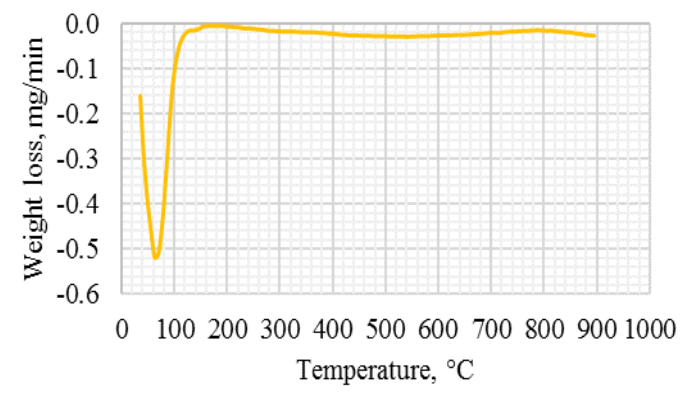

(c)

Fig. 2. TG curve for PTES-SBA-15 using direct synthesis at (a) calcination $550^{\circ} \mathrm{C}$ for 5 hours (b) calcination $550^{\circ} \mathrm{C}$ for 3 hours and (c) calcination $350^{\circ} \mathrm{C}$ for 3 hours
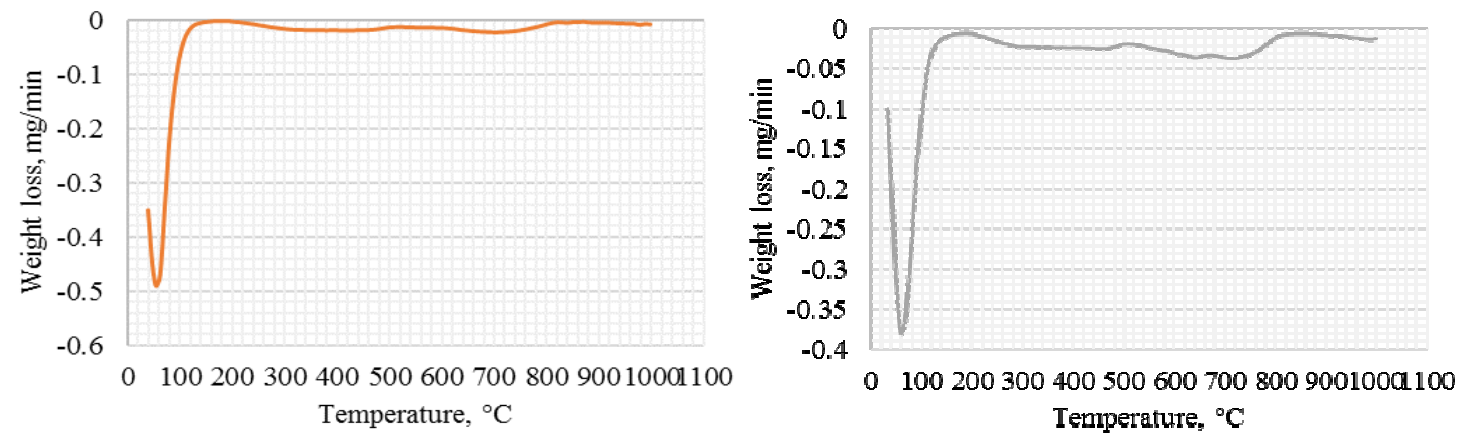

(a) (b)

Fig. 3. TG curve for PTES-SBA-15 using post-grafting at (a) calcination at $450^{\circ} \mathrm{C}$ (b) calcination at $750^{\circ} \mathrm{C}$

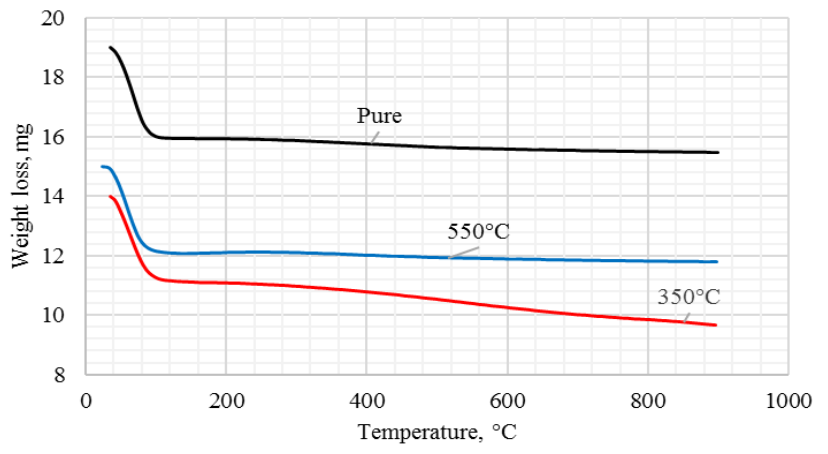

— SBA-15 — PTES-SBA-15(350) — PTES-SBA-15(550)

(a)

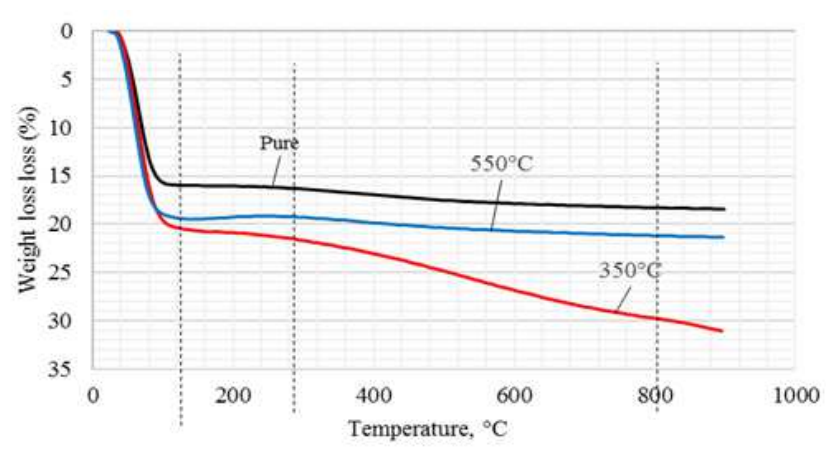

-SBA-15 PTES-SBA-15(350) -PTES-SBA-15(550)

(b)

Fig. 4. (a) Weight loss curves of PTES-SBA-15 of different curing temperature using direct-synthesis (b) Weight loss percentage curves of PTES-SBA-15 of different curing temperature using direct-synthesis 


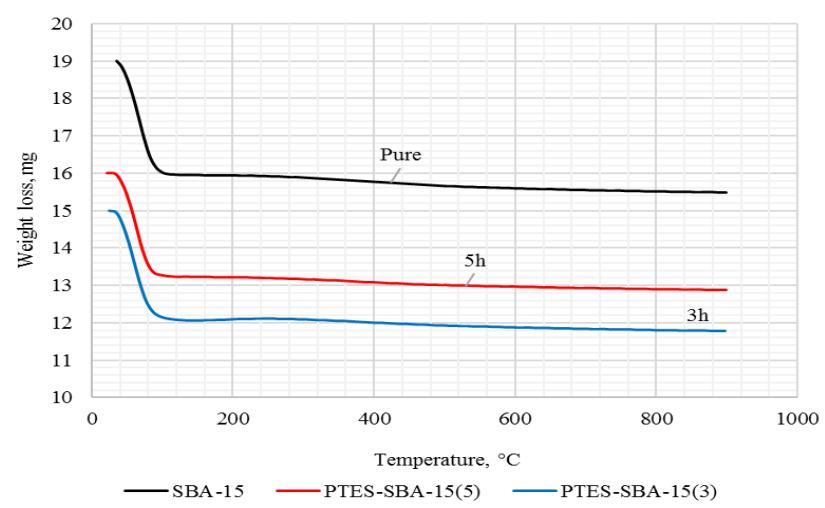

(a)

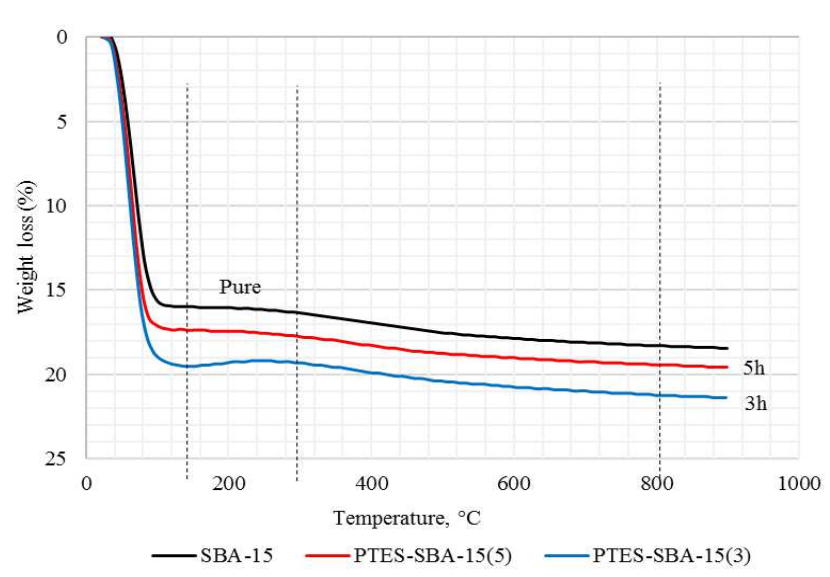

(b)

Fig. 5. (a) Weight loss curves of PTES-SBA-15 of different calcination duration time using direct-synthesis (b) Weight loss percentage curves of PTES-SBA-15 of different calcination duration time using direct-synthesis method.

However, it can be concluded that the duration time of calcination does not significantly influence the effectiveness of surfactant removal due to insignificant difference of weight loss displayed from TG curve.

For region between 300 to $800^{\circ} \mathrm{C}$, the weight loss of both functionalized samples does not much differ from pure SBA-15. The decomposition of PTES is very small which indicates that phenyl group does not effectively incorporate into the surface of SBA-15 in this study. It can be concluded that the duration time of calcination does not significantly affect the effectiveness of phenyl group incorporation into SBA15 mesostructure.

\section{TGA Profile of PTES-SBA-15 at Different} Calcination Temperature by Post-Grafting Method

The region between 25 to $150^{\circ} \mathrm{C}$ for Fig. 6 shows higher weight loss for pure SBA-15 than functionalized sample. This indicates that the content of adsorbed water of pure SBA-15 is higher than PTES-SBA-15(450) and PTES-SBA-15(750) due to the absence of functional group which could hinder the water adsorption by mesostructure.

For region with temperature range of 150 to $300^{\circ} \mathrm{C}$, the weight loss of PTES-SBA-15(750) shows equal amount to PTES-SBA-15(450). This could be explained by the same amount of unremoved surfactant at calcination temperature of 450 and $750^{\circ} \mathrm{C}$. This may conclude that for post grafting method, calcination temperature above $450^{\circ} \mathrm{C}$ is effective for surfactant removal process.

A higher weight loss is observed for region at temperature ranged 300 to $800^{\circ} \mathrm{C}$ than other regions. PTES-SBA-15(750) shows the highest weight loss indicating that high amount of phenyl group decompose at this region. It can be hypothesized that phenyl group was effectively incorporated at higher calcination temperature by using post-grafting method into the mesostructure of SBA-15.

\section{TGA Profile of PTES-SBA-15 at Different Method of Functionalization}

Figure $7 \mathrm{a}$ and $\mathrm{b}$ compares TGA profile of PTESSBA-15 for different method of functionalization. PTES-SBA-15(P) indicates the functionalization by post-grafting while PTES-SBA-15(D) by direct synthesis method. Both methods undergo calcination at temperature of $550^{\circ} \mathrm{C}$.

For temperature 25 to $150^{\circ} \mathrm{C}$, PTES-SBA- $15(\mathrm{P})$ shows lower weight loss compared to pure SBA-15 and PTES-SBA-15(D). This was probably due to small amount of adsorbed water contained in PTESSBA-15(P). PTES-SBA-15(D) shows higher weight loss which could be attributed to decomposition of some unreacted PTES during synthesis of material.

PTES-SBA-15(P) shows higher weight loss than PTES-SBA-15(D) at TG curve region of temperature $150-300^{\circ} \mathrm{C}$. Therefore, it can be concluded that removal of surfactant by calcination is more effective by direct synthesis method.

PTES-SBA-15(P) shows higher weight loss than PTES-SBA-15(D) in the region of $300-800^{\circ} \mathrm{C}$ due to higher decomposition of phenyl group, PTES and less than $1 \%$ weight loss at temperature at above $800^{\circ} \mathrm{C}$, which could be attributed to phenyl group functionalized in deeper internal microstructure of SBA-15. This indicates that post-grafting method exhibits better incorporation of phenyl group in internal mesostructure surface of SBA-15 (García et al., 2007). Direct method shows lower degree of functionalization as the weight loss is not much differ from pure SBA-15. 


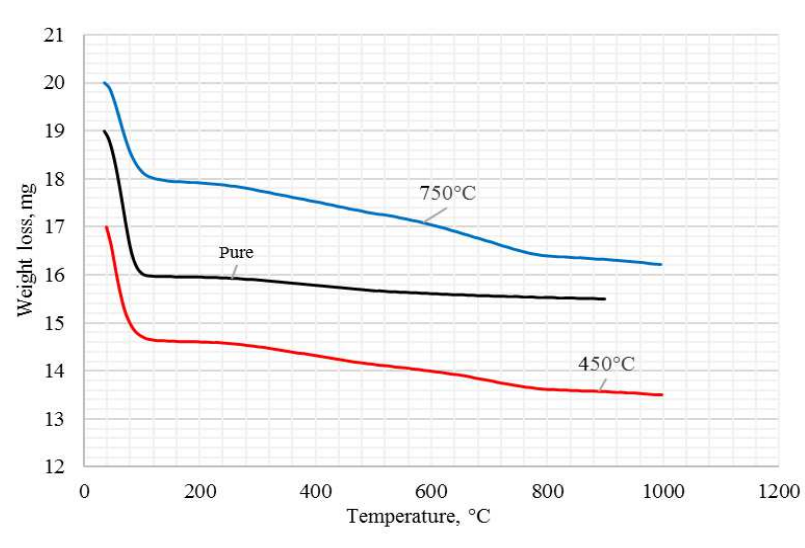

-SBA-15 PTES-SBA-15(450) PTES-SBA-15(750)

(a)

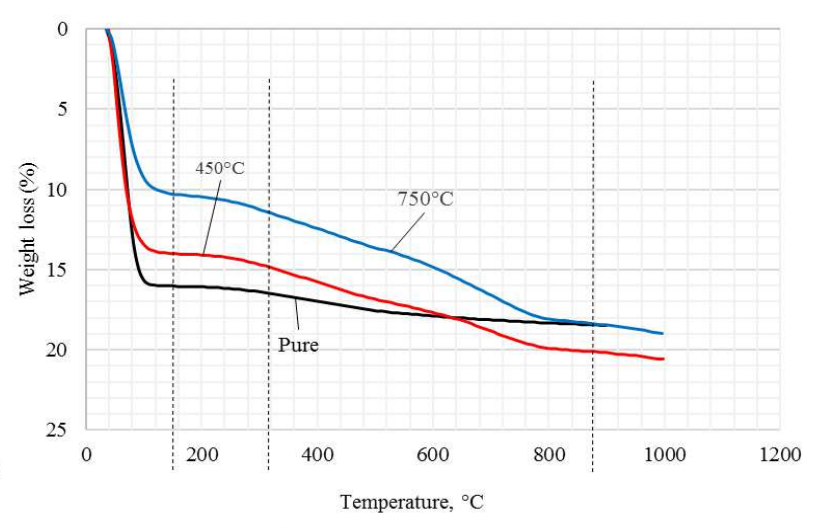

—SBA-15 —PTES-SBA-15(450) —PTES-SBA-15(750)

(b)

Fig. 6. (a) Weight loss curves of PTES-SBA-15 of different calcination temperature using post-grafting (b) Weight loss percentage curves of PTES-SBA-15 of different calcination temperature using post-grafting

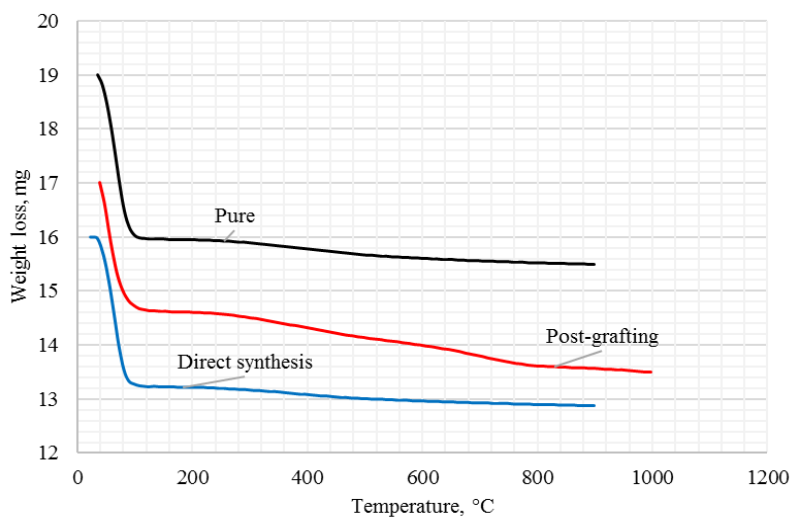

—SBA-15 —PTES-SBA-15(P) —PTES-SBA-15(D)

(a)

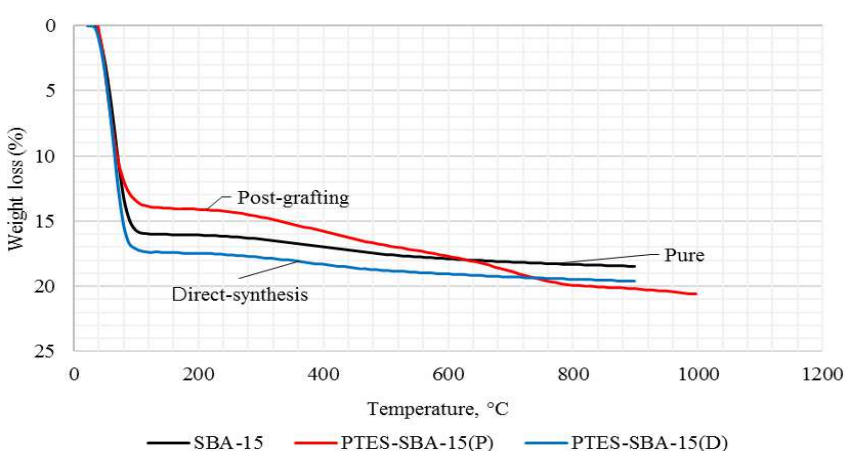

(b)

Fig. 7. (a) Weight loss curves of PTES-SBA-15 of method of functionalization (b) Weight loss percentage curves of PTES-SBA-15 of different method of functionalization

\section{Conclusion}

It can be concluded that, for direct synthesis method, the different temperature of calcination could affect the effectiveness of surfactant removal and amount of PTES incorporated into SBA-15. Calcination at lower temperature of $350^{\circ} \mathrm{C}$ provides higher degree of functionalization. Duration of calcination, however, does not largely influence the effectiveness of surfactant removal and incorporation of PTES. This finding for direct synthesis method is contradict with post-grafting method in which the results of calcination at higher temperature, $750^{\circ} \mathrm{C}$ shows larger amount of PTES able to be incorporated into internal surface of SBA-15.

\section{Acknowledgement}

This project is funded by Fundamental Research Grant (FRGS/2/2013/TK05/UITM/03/2) from Ministry of High Education Malaysia. Special thanks to Research Management Institute (RMI) Universiti Teknologi MARA for the special assistance in alleviating the execution of this project.

\section{Author's Contributions}

Norhasyimi Rahmat: Principal investigator who design the experiment and lead the investigation.

Nurjihan Sadon: Research assistant.

Muhammad Abeed Yusof: Research assistant.

\section{Ethics}

This study is investigated to observe the effect of calcination temperature and duration time characterized by thermal analysis, which is being explored for this range temperature and time with specific silica 
precursor. This study is not replicated or duplicated from any other study. In fact, this study would contribute to further understands and acknowledge the importance of thermal analysis towards different properties of catalysts.

\section{References}

Benamor, T., L. Vidal and B. Lebeau, 2012. Influence of synthesis parameters on the physico-chemical characteristics of SBA-15 type ordered mesoporous silica. Microporous Mesoporous Mater., 153: 100-114. DOI: $10.1016 /$ j.micromeso.2011.12.016

Brodie-Lindera, N., G. Dosseha, C. Alba-Simonescob, F. Audonnetb and M. Impéror-Clercc, 2008. SBA-15 synthesis: Are there lasting effects of temperature change within the first $10 \mathrm{~min}$ of TEOS polymerization? Mater. Chem. Phys., 108: 73-81. DOI: 10.1016/j.matchemphys.2007.09.007

Calvoa, A., M. Joselevichc, G.J.A.A. Soler-Illiaa and F.J. Williams, 2009. Chemical reactivity of aminofunctionalized mesoporous silica thin films obtained by co-condensation and post-grafting routes. Microporous Mesoporous Mater., 121: 67-72. DOI: $10.1016 /$ j.micromeso.2009.01.005

Filiz, S. and Y. Ayşen, 2012. Surface functionalization of SBA-15 particles for amoxicillin delivery. Microporous Mesoporous Mater., 158: 281-291. DOI: 10.1016/j.micromeso.2012.02.037

García, N., E. Benito, J. Guzmána, P. Tiembloa, V. Moralesb and R.A. Garcíab, 2007. Functionalization of SBA-15 by an acid-catalyzed approach: A surface characterization study. Microporous Mesoporous Mater., 106: 129-139. DOI: $10.1016 /$ j.micromeso.2007.02.043

Giaquinto, A.P., 2012. Synthesis, modification and chracterization of spherical SBA-15 ordered mesoporous silica and evaluation in high performance liquid chromatography. Seton Hall University, South Orange, New Jersey.

Gokulakrishnana, N., T. Karbowiakb, J.P. Bellatb, L. Vonnaa and M.A. Saadaa et al., 2013. Improved hydrophobicity of inorganic-organic hybrid mesoporous silica with cage-like pores. Colloids Surfaces A: Physicochemical Eng. Aspects, 421: 34-43. DOI: $10.1016 /$ j.colsurfa.2012.11.066

Huang, Z., L. Huang, S.C. Shen, C.C. Poh and K. Hidajat et al., 2005. High quality mesoporous materials prepared by supercritical fluid extraction: Effect of curing treatment on their structural stability. Microporous Mesoporous Mater., 80: 157-163.

DOI: 10.1016/j.micromeso.2004.12.016
Johansson, E.M., 2010. Controlling the pore size and morphology of mesoporous silica.

Klimovaa, T., A. Esquivela, J. Reyesa, M. Rubiob and X. Bokhimic et al., 2006. Factorial design for the evaluation of the influence of synthesis parameters upon the textural and structural properties of SBA15 ordered materials. Microporous Mesoporous Mater., 93: 331-343.

DOI: 10.1016/j.micromeso.2006.03.016

Kruk, M. and M. Jaroniec, 2001. Gas Adsorption characterization of ordered organic-inorganic nanocomposite materials. Chem. Mater., 13: 3169-3183. DOI: $10.1021 / \mathrm{cm} 0101069$

Ko, C.H. and R. Ryong, 2000. Characterization of the Porous Structure of SBA-15. Department of Chemistry and School of Molecular Science (BK21). Korea Advanced Institute of Science and Technology, Korea.

Li, G., M. Kanezashi and T. Tsuru, 2011. Preparation of organic-inorganic hybrid silica membranes using organoalkoxysilanes: The effect of pendant groups. J. Membrane Sci., 379: 287-295. DOI: 10.1016/j.memsci.2011.05.071

Matheron, M., A. Bourgeois, T. Gacoin, A. Brunet-Bruneau and P.A. Albouy et al., 2006. Mesoporous 3Dhexagonal organosilicate films: Post-synthesis grafting Vs. direct synthesis. Thin Solid Films, 495: 175-179. DOI: 10.1016/j.tsf.2005.08.262

Norhasyimi, R., A.Z. Abdullah and A.R. Mohamed, 2010. A review: Mesoporous santa barbara amorphous-15, types, synthesis and its applications towards biorefinery production. Am. J. Applied Sci., 7: 1579-1586. DOI: 10.3844/ajassp.2010.1579.1586

Rowsell, J.L.C. and O.M. Yaghi, 2004. Metal-organic frameworks: A new class of porous materials. Microporous Mesoporous Mater., 73: 3-14. DOI: 10.1016/j.micromeso.2004.03.034

Wua, Z., H. Xiangc, T. Kima, M.S. Chund and K. Leea, 2006. Surface properties of submicrometer silica spheres modified with aminopropyltriethoxysilane and phenyltriethoxysilane. J. Colloid Interface Sci., 304: 119-124. DOI: 10.1016/j.jcis.2006.08.055 